\title{
Entre la literatura i la divulgació científica: les novel·les de Martí Domínguez
}

\section{Literature and popularization of science in the novels by Martí Domínguez}

\begin{abstract}
Martí Domínguez (1966) is a biologist, writer and journalist, the author of novels, essays, and press articles. In his novels Les confidències del comte de Buffon (1997) and El secret de Goethe (1999), he presents two great personalities of 18th century Europe and a scientific and cultural context of their lives and works. These novels contain information about debates, ideas, and theories related to the development of science (especially the natural sciences) in the Age of Enlightenment. In the article we study the narrative strategies used by the author in order to present issues regarding the history of natural sciences in modern Europe.
\end{abstract}

Barbara Łuczak

Pracownia Katalonistyki, Instytut Filologii Romańskiej, Uniwersytet im. Adama Mickiewicza w Poznaniu, al. Niepodległości 4, 61-874 Poznań e-mail: basia@amu.edu.pl

Keywords: contemporary Catalan literature, Martí Domínguez, popularization of science, science in literature

\section{INTRODUCCIÓ}

L'any 2004, en una ressenya apareguda en la revista Caràcters, Julià Guillamon $(2004$, p. 23) observava un "espai nou" en la literatura catalana que haurien creat les novel·les de Martí Domínguez (1966) publicades fins aquella data, a saber, Les confidències del comte de Buffon (Una època de la natura) (1997) i El secret de Goethe (1999) ${ }^{1}$. La novetat de la seva producció consistiria

\footnotetext{
${ }^{1}$ Un esbós d'aquest article, en la part corresponent a l'anàlisi de Les confidències del comte de Buffon, va ser presentat en forma de comunicació en el 15è Col·loqui Internacional de la North American Catalan Society (Barcelona, 29-30 de juny i 1 de juliol de 2015). La recerca necessària per completar el treball s'ha emmarcat en el projecte d'investigació "Formes de vida, formes de literatura", finançat pel Ministeri de Ciència i Ensenyament Superior de Polònia, en base a la decisió núm. 0237/NPRH4/H2b/83/2016 (NPRH).
} 
a haver trobat una fórmula -reeixida $i$, en tot cas, reconeguda ${ }^{2}$ - per combinar el format literari amb continguts "científics". I encara que el mateix Guillamon aportava alguns exemples de textos novel-lescos semblants o afins en diferents aspectes a les propostes narratives de Domínguez (El camí de Vincennes [1995] d'Antoni Marí o L'Atles furtiu [1998] d'Alfred Bosch), no hi ha dubte que el projecte que duu a terme l'escriptor valencià destaca per la seva solidesa. La llista de les seves obres narratives inclou, entre d'altres ${ }^{3}$, la novel·la El retorn de Voltaire (2007), la qual, juntament amb els dos llibres esmentats més amunt, forma una mena de tríptic sobre el Segle de les Llums. En aquest cicle l'autor ens ofereix històries construïdes entorn de figures eminents de la ciència i la cultura del segle XVIII, pintades sobre el canemàs de temes, debats i conflictes que van marcar la vida intel·lectual de l'Europa d'aquella època. D'altra banda, els volums Peiximinuti (1993) i Bestiari (2000) recullen articles breus, la majoria dels quals constitueix el comentari d'algun fenomen relacionat amb les ciències biològiques, tractat, però, dins d'un context cultural ampli: literari, antropològic, filosòfic, estètic... ${ }^{4}$ Per la seva part, El somni de Lucreci $(2013)^{5}$ reconstrueix alguns episodis de l'apassionant història de les influències que el poema De rerum naturae ha exercit en la ciència $i$ cultura europees a partir del seu (re)descobriment a principis del segle XV; alhora que presenta els models que Domínguez (2014) segueix en la seva escriptura i, a la vegada, deixa entreveure les seves inquietuds i objectius:

La Il·lustració $[\ldots]$ no sols és aquest sapere aude, no sols és aquest pas del sedàs de l'experiència i de la crítica, sinó que també duu aparellada una forma, una publicitat, una actitud pública i, en alguns casos, de combat ideològic. És la unió de la ciència i de la literatura per a fer publicitat d'una idea justa i gosar canviar el món. [...] La perillositat de les Llums no radicava tan sols en les noves idees, sinó també en la forma atractiva i popular de presentar-les. [...] Sovint s'oblida aquesta característica fonamental de la popularització del coneixement. Al capdavall, l'estil fa la Il·lustració. I aquest estil consisteix bàsicament a difondre el saber. (pp. 146-147)

En llegir aquestes paraules resulta difícil sostreure's a la impressió que el projecte de divulgació científica i de combat ideològic que s'hi formula com a mostra de responsabilitat intel·lectual es refereix -guardant les distànciesa l'obra literària i periodística del mateix Martí Domínguez. D'altra banda, ja la simple lectura dels títols del seu tríptic dedicat al segle XVIII (tema que a la llum

${ }^{2}$ Les confidències del comte Buffon ha estat guardonada amb els premis Andròmina (1997) i el Crexells (1998), mentre que El secret de Goethe ha rebut el Prudenci Bertrana de novel·la (1999).

${ }^{3}$ Domínguez també és l'autor de les novel·les El fracassat (2013) i La sega (2015).

${ }^{4}$ Sobre Bestiari diu l'autor: "[S]ón textos [...] per on han desfilat els meus escriptors i científics més estimats, tots ells acompanyats de l'inesgotable repertori d'anècdotes que naixen de la interacció de l'home amb la natura" (Domínguez, 2000a, p. 10).

${ }^{5}$ Guardonat amb el Premi Carles Rahola d'assaig, l'any 2013. Per la matèria que tracta i per la manera de presentar-ne els continguts, el llibre de Domínguez s'inscriu en la fórmula de l'assaig divulgatiu. 
de la darrera citació no sembla que sigui cap casualitat) ens demostra que els continguts d'aquest projecte s'atenen a un pla ben definit. Es tracta de presentar figures eminents -Buffon, Goethe, Voltaire-en l'obra dels quals l'interès per les ciències naturals es combina amb la creació literària en el sentit propi de la paraula $o$-en el cas de Buffon- amb una sensibilitat i consciència estètiques. I si l'estil del segle XVIII -d'acord amb l'opinió expressada en el fragment citat"consisteix bàsicament a difondre el saber", és interessant preguntar-se quines són les característiques de l'estil del mateix Domínguez, elaborat i emprat per a la divulgació de coneixements avui en dia. Per contestar aquesta pregunta em centraré en el comentari de les seves primeres novel-les: Les confidències del comte de Buffon i El secret de Goethe. He triat aquestes dues obres perquè, d'una banda, les figures històriques que s'hi recreen posen en relació els dos dominis de l'activitat humana que interessen a l'autor -és a dir, les ciències naturals i la literatura- i, de l'altra, en cert sentit resulten complementàries. L'escriptor destaca aquest vincle quan observa:

Goethe sempre recordarà que va nàixer el mateix any que es varen publicar els primers volums de la Història natural de Buffon, l'any $1749^{6}$. Si Buffon aspirava a fer literatura des de la ciència, Goethe representa el cas contrari: el d'un lletraferit interessat per la ciència. Buffon és un excel·lent naturalista que escriu de manera excelsa, Goethe és un excepcional escriptor que s'interessa de manera molt brillant per les idees científiques del seu temps. (Domínguez, 2010, p. 33) ${ }^{7}$

Ara bé, les consideracions de Domínguez sobre el paper que els aspectes estilístics van desenvolupar en la tasca de popularització del coneixement en el segle XVIII (consideracions que, a primer cop d'ull, podrien semblar fins i tot una mica exagerades), troben un sentit més precís quan les posem en relació amb les idees $\mathrm{i}$ inquietuds estètiques dels autors que l'escriptor valencià recrea en les seves novel·les.

\section{LES CONFIDÈNCIES DEL COMTE DE BUFFON}

A l'inici de la redacció de Les confidències ${ }^{8}$ Martí Domínguez era, sens dubte, ben conscient que en l'activitat científica de Buffon l'estudi de la natura

\footnotetext{
${ }^{6}$ Efectivament, a El secret de Goethe el poeta també recorda aquest fet (Domínguez, 2000, p. 174).

${ }^{7}$ Òbviament, en el cas de Goethe, aquesta "complementarietat" s'observa no només en el simple fet de dedicar-se paral·lelament a la literatura i a l'especulació científica, sinó també en la manera com aquestes dues activitats es relacionen en el seu pensament: "Goethe embodied his belief that science and poetry, with their corresponding conceptions of nature, are not incompatible but actually complementary" (Miller, 2009, p. xxiii).

${ }^{8}$ A partir d'aquí (amb l'excepció del títol del tercer apartat) utilitzo les versions abreujades: Les confidències i El secret.
} 
s'uneix, precisament, amb la reflexió sobre l'estil; és a dir, la natura esdevé el denominador comú de les observacions tant sobre la història del món i de les seves formes, com sobre la manera d'escriure ${ }^{9}$. És la raó per la qual el narrador de la novel·la, en una d'aquestes intervencions (que, certament, pequen de convencionals) s'interroga sobre la seva pròpia manera d'entendre el concepte d'estil: "Però què entenia jo per "estil"?" (Domínguez, 1997, p. 131). No obstant aquesta evident càrrega retòrica, la pregunta no ens semblarà gratuïta si prenem en compte que l'any 1753, a l'edat de 46 anys, Buffon, un dels naturalistes més importants dels segle XVIII, és admès a l'Académie Française i el seu discurs d'ingrés està dedicat precisament a la problemàtica de l'estil (en les edicions de les seves obres apareixerà amb el títol Discurs sobre l'estil [Discours sur le style]). Tant és així que, com observa el biògraf Jacques Roger, molts -en particular els detractors de la seva obra científica- han considerat Buffon sobretot - si no únicament- un (hàbil) escriptor ${ }^{10}$. Ell mateix va insistir en el paper que la manera de presentar les idees exercia en el procés de recepció dels continguts científics quan escrivia:

Les obres ben escrites [...] seran les úniques que passaran a la posteritat: la quantitat de coneixements, la singularitat dels fets, la novetat dels descobriments no són garanties d'immortalitat; si les obres que les contenen no es desenvolupen sinó sobre petits temes, si estan escrits sense gust, sense noblesa i sense enginy, desapareixeran, perquè les coneixences, els fets i els descobriments es lleven fàcilment, es transporten i fins i tot guanyen escrites en altres obres per mans més hàbils. L'estil no pot ni furtar-se, ni transportar-se, ni alterar-se; si és elevat, noble, sublim, l'autor serà igualment admirat en tots els temps, perquè sols la veritat és perenne, i, fins i tot, eterna. (Domínguez, 1997, p. 133) ${ }^{11}$

Per a Buffon, el concepte d'estil no es redueix, ni molt menys, al conjunt de solucions lingüístiques escollides per l'autor, ja que inclou també -0 abans de

\footnotetext{
${ }^{9}$ Val a dir que el fragment de El somni de Lucreci citat al principi d'aquest article es troba justament al final d'un apartat dedicat a presentar l'art literari de Buffon.

${ }^{10}$ Condorcet escrivia: "Me voici encore occupé d'un autre charlatan, du grand Buffon. Plus je l'étudie, plus je le trouve vide et enflé. Heureusement que celui-ci avait beaucoup d'esprit, des aperçus heureux et un grand talent pour écrire" (apud Hoquet, 2005). Malesherbes (1798) constatava, en una línea semblant: "En effet, il est certain que ceux pour qui M. de Buffon a écrit ne sont point les naturalistes ; je suis même persuadé que quand il a entrepris son ouvrage, il les connoissoit à peine de nom. Ceux dont il a cherché l'approbation sont, selon les apparences, les gens du monde, les gens d'esprit, les gens de goût; et la beauté de son style, surtout les traits brillans dont son ouvrage est rempli, lui assurent à jamais leurs suffrages" (p. 107). D'Alembert, per la seva part, anomenava Buffon "le grand phrasier" ("el gran frasista"), no sense un gra de malícia (vg. Roger, 1989, p. 10), mentre que Rousseau afirma: "c'est la plus belle plume de son siècle ; je ne doute point que ce ne soit là le jugement de la postérité" (Rousseau, 1826, p. 447).

${ }^{11}$ Cito en versió catalana els fragments de les obres de Buffon reproduïts en la novel·la de Domínguez. Les altres citacions es fan a partir dels originals francesos.
} 
tot- els esquemes d'organització del text; l'estil és "l'ordre i el moviment que posem als pensaments" (Domínguez, 1997, p. 131), afirma en el Discurs. Estructurar un text significa trobar una relació adient entre les diferents idees generals $i$, en el següent pas, entre aquestes i d'altres que n'emanen, de caràcter secundari i accessori. Aquest pla inicial és la base de l'estil i allò que li assegura unitat. I afegim de seguida que en l'argumentació buffoniana la unitat és una noció de valor considerable. És el tret gràcies al qual una obra concebuda per l'ésser humà pot apropar-se a les obres de la natura, que són perfectes perquè cadascuna constitueix un tot elaborat "sobre un pla etern". En un acte creatiu, la natura -escriu Buffon- esbossa la forma de cada ésser viu i la desenvolupa, pacientment i silenciosa, sense desviar-se mai del camí establert. L'esperit humà, per la seva banda, no pot crear res, però en emprendre el camí marcat per la natura i en sotmetre els seus coneixements a un pla únic -és a dir, en organitzarlos en un sistema-, pot arribar a produir una obra immortal (vg. Buffon, 1843, p. 7).

Aquesta relació intrínseca entre l'escriptura entesa com a disposició adequada dels continguts i la natura és la clau per entendre la problemàtica de l'estil en Buffon. En un altre moment l'autor del Discurs sobre l'estil constata:

Per a ben escriure, cal posseir plenament el tema; cal reflexionar llargament sobre l'ordre de les idees, i formar una seguida, una cadena contínua, on cada punt representa una idea; i quan s'haurà pres la ploma, caldrà conduir-la successivament sobre el primer traç, sense permetre-li allunyar-se, sense recolzar-la desigualment, sense deixar-li fer cap altre moviment que aquell que està determinat per l'espai que ha de recórrer. (Domínguez, 1997, p. 132)

En aquest fragment és significativa la força amb què Buffon insisteix sobre el caràcter continu del procés d'escriptura: "formar una seguida, una cadena contínua" d'idees, "conduir-la successivament", "sense permetre-li allunyar-se" són fórmules que expressen la importància que li atorga. Subratllo aquest element tot recordant que Buffon és l'autor de la monumental Història natural (Histoire Naturelle), que es va anar publicant, en 44 volums, durant més de 40 anys $^{12}$. És aquí on destaca, justament, el caràcter processual del treball de la natura. I no cal dir que la coincidència entre el títol d'un altre tractat de Buffon (Les èpoques de la natura [Les époques de la nature], 1779) i el subtítol de la novel·la de Domínguez ("una època de la natura") no és de cap manera casual. En l'última frase de la novel·la llegim: "[...] aquesta ha estat, en definitiva, la millor part de la meua vida, el millor tros de la meua història natural" (Domínguez, 1997, p. 224).

${ }^{12}$ L'objectiu d'aquest magne projecte -continuat per un altre autor després de la mort del naturalista- va ser caracteritzar tots els regnes de la natura, encara que, en definitiva, Buffon es va limitar a parlar dels minerals i d'una part del regne dels animals. 
Efectivament, Les confidències, una pretesa autobiografia d'un dels més destacats naturalistes europeus del Segle de les Llums, està pensada com una mena d'"història natural". La veu narrativa pertany al mateix George-Louis Leclerc, comte de Buffon, que, en un discurs autobiogràfic diguem-ne "clàssic" -una exposició suposadament "sincera" dels esdeveniments que van marcar la seva existència $i$ van formar-ne el caràcter- dóna compte de la seva vida i la seva activitat científica, situant ambdues en un panorama força ampli de la vida cultural, intel·lectual i científica de la Il·lustració francesa. Es tracta d'un subjecte que "s'explica" i que mitjançant allò que diu i com ho diu, crea la seva identitat $i$ es dóna a conèixer: "L'estil fa l'home" (Domínguez, 2005, p. 133), escrivia Buffon en el seu Discurs sobre l'estil. La "naturalitat" -entesa ja en un altre sentit- es reflecteix també en la recerca de la confiança i de la complicitat del lector per part del narrador. I, com que Buffon insistia a fer correspondre l'estil a un contingut precís ${ }^{13}$, el discurs del narrador és concebut com una mena de confessió dirigida a l'"estimat lector" (en les primeres paraules del relat homodiegètic), que tendeix a aclarir i completar la biografia "oficial" del naturalista, particularment en allò que concerneix les motivacions d'algunes actituds adoptades per Buffon i les decisions que va (o no va) prendre ${ }^{14}$. Paral·lelament, l'autor procura assegurar-li una suposada "autenticitat". Per assolir aquest objectiu, en el preàmbul de la novel·la recorre al joc literari, de llarga tradició i que més endavant reprendrà en $E l$ secret, que consisteix de presentar el text com un manuscrit; les confidències del comte de Buffon serien llavors la transcripció d'unes pàgines trobades miraculosament en un vell cofre arraconat als soterranis del Museu Nacional d'Història Natural, al Jardin des Plantes parisenc.

L'evocació del concepte d'història en el projecte de narració d'una vida particular és perfectament comprensible i, com a tal, no sembla requerir cap comentari. El temps és "el gran obrer de la natura" ("le grand ouvrier de la nature"), deia Buffon en la seva Història natural, i el seu esforç es nota igualment en la construcció del relat autobiogràfic de Les confidències. La vida i la formació de l'individu hi és presentada com un procés que es realitza en el temps, que el temps estructura i determina, tot donant-li substància i sentit. El relat, d'estructura lineal -contínua, unidireccional i de fil únic, com aconsellava Buffon en el fragment citat anteriorment-, segueix llavors l'ordre cronològic: comença amb el naixement del narrador $i$ es desenvolupa fent referència a la

13 "Le ton n'est que la convenance du style à la nature du sujet; il ne doit jamais être forcé; il naîtra naturellement du fond même de la chose [...]" (Buffon, 1843, p. 10).

${ }^{14}$ En el text trobem les fórmules que posen de manifest la pretesa "sinceritat" del narrador: "la veritat és que", "us confesse", "haig de reconèixer tot i que em dolga i que ara em produesca una inevitable vergonya", "creu-me, lector" (Domínguez, 2005, pp. 44, 51, 52 i 55), etc. 
successió de les etapes de la vida humana: la infància, l'adolescència, la joventut i l'època de la maduresa fins a l'edat de setanta-vuit anys, que és quant la narració se suspèn. En segon lloc, la importància del factor temporal en la vida del narrador es fa palesa també en la successió de polèmiques, debats i descobriments que van marcar el segle XVIII a Europa i al món i, en particular, en el desenvolupament del pensament del mateix Buffon. Tot això és vist des de la perspectiva d'un narrador dissenyat segons un model de savi que -no sense un punt d'autocomplaença- contempla la realitat des d'una certa distància, sent capaç de relativitzar les fortunes i adversitats que li porta la vida. Aquest tret fa que la narració progressi fluidament $i$ serena, malgrat les polèmiques $i$ els conflictes que van marcar la vida i l'època de Buffon i que són evocats per Domínguez. Probablement és en aquest sentit que l'autor assegurava en una entrevista que "El Comte de Buffon [li] va permetre oferir una visió amable del XVIII" (Castells, 2007).

Ara bé, en un article dedicat a aclarir alguns aspectes de la problemàtica del temps en el pensament de Buffon, Hoquet (2010, p. 43) ens recorda que el sentit temporal del concepte d' "història" deriva majoritàriament d'una visió elaborada al segle XIX. En canvi, al segle XVIII la història es conceptualitza d'una manera força més àmplia; i és en aquesta època quan Buffon concep i redacta la seva Història natural, l'elaboració de la qual és un dels eixos temàtics que vertebra el discurs ficcional del narrador del llibre de Domínguez, de la mateixa manera que va vertebrar tota l'activitat científica de Buffon. Malgrat la seva dimensió temporal, la història pot designar també un mode de descripció o d'investigació, un mètode general compartit per diferents tipus d' "historiadors", independentment del seu objecte d'estudi (que pot ser tant l'Imperi Romà com el regne mineral). En aquest model metodològic de recerca, que Buffon segueix en la seva Història natural, el coneixement es basa en (i en realitat emana de) l'acumulació i l'examen minuciós de monuments i proves (Hoquet, 2010, p. 44). En Les èpoques de la natura Buffon escrivia:

A l'igual que en la història civil es consulten els títols, es busquen les medalles, es desxifren les inscripcions antigues, per determinar les èpoques de les revolucions humanes, les dades dels diferents esdeveniments morals; de la mateixa manera cal furgar en els arxius del món, traure de les entranyes de la terra els vells monuments, recollir-ne les ruïnes i reunir en un conjunt de proves tots els indicis dels canvis físics que poden delimitar-nos les diferents edats de la natura. (Domínguez, 2005, p. 202)

Cito aquest fragment, reproduït en el capítol que justament es titula "Les èpoques de la natura" (fórmula recollida, com recordem, en el subtítol del llibre), per destacar un element que pot aclarir certs aspectes de l'estructura de la novel·la. La recerca en els arxius i la recol·lecció de proves per donar una visió 
àmplia i panoràmica ${ }^{15}$-que, en definitiva, privilegia el factor espacial sobre el temporal en la pintura de l'univers ficcional- són, de fet, els procediments que l'escriptor valencià ha emprat a l'hora de contar la història de Buffon. "Per a ben escriure, cal posseir plenament el tema", deia l'autor del Discurs sobre l'estil, en un fragment citat anteriorment. Així mateix, Domínguez procura presentar de forma sintètica alguns episodis de la història de la ciència del segle XVIII. Hi trobem esbossat un retrat de la vida als salons freqüentats per filòsofs, naturalistes o matemàtics, entrem als seus despatxos, cabinets, laboratoris, i fem conversa -força estereotipada, de temes i formes previsibles, això sí- sobre els continguts relatius a diferents disciplines de la ciència, etc. Aquest panorama està recreat no sense cert gust per l'enciclopedisme, també característic del segle XVIII - no cal dir-ho-, un tret que en l'escriptura de Domínguez observava Sòria (2004, p. 27), tot parlant de la seva activitat d'articulista. Els personatges que desfilen per les planes de la novel-la hi apareixen sovint amb uns "atributs" fàcilment recognoscibles $-\mathrm{O}$, en algun cas, reduïts a aquests atributs-, els quals poden consistir tant en una qualitat que identificava tal filòsof o tal artista, com en la seva obra més cèlebre. Aquestes marques distintives estan destinades a quedar-se en l'imaginari dels lectors com una mena de tret definitori, element que reforça el caràcter didàctic del text ${ }^{16}$. En aquest sentit cal observar que la tasca de divulgació que l'autor mira de dur a terme en la seva narrativa implica una inevitable simplificació i esquematització en la representació de les figures $i$ en l'exposició de continguts, que en aquesta primera novel·la de Domíguez resulta particularment visible.

La història entesa com a model metodològic, que Buffon aplica en la recerca $-\mathrm{i}$ que Domínguez sembla intentar reproduir en el seu llibre ${ }^{17}-$, troba confirma-

${ }^{15}$ Guillamon (2007, p. 23), en un comentari ja esmentat, anomenava Les confidències "una novel·la panoràmica".

${ }^{16}$ De manera que Rousseau hi és presentat com un individu insegur de si mateix, poruc, que, malgrat ser l'autor d'un tractat de pedagogia, abandona els seus fills a l'hospici. El retrat de Voltaire està marcat, a pesar del geni que caracteritza el filòsof, per un seguit de petiteses humanes i una polèmica que va mantenir amb Buffon sobre l'origen dels fòssils, ridícula -tot sigui dit- si ens fixem en les teories exposades pel "savi de Ferney". S'hi evoquen igualment les figures de Madame de Châtelet, una de les dones més instruïdes i intel·ligents de l'època; el naturalista René Antoine de Réamur, com aquell que percep en la natura la impremta divina i que s'oposa a Buffon quant a la presumpció d'una ciència alliberada del principi transcendent (d'aquesta manera la novel·la articula la denúncia de les institucions de poder que pretenen controlar o coartar la ciència, un tema que s'inscriu en la línia de combat ideològic esmentada anteriorment); Abraham Tremblay, el primer estudiós dels pòlips, que tant d'interès van despertar en els cercles il·lustrats per haver plantejat el problema de la distinció entre els minerals, els vegetals i els animals, així com el de la relació entre les diferents formes de la matèria; el matemàtic Pierre-Louis Maupertuis, i molts altres.

${ }^{17}$ En aquest mateix sentit Guillamon apuntava: "En la seva primera novel·la, Martí Domínguez reconstrueix la vida de Buffon, fent servir un mètode que fins a un cert punt recorda el de la 
ció en el seu mètode de descripció dels organismes vius i, en definitiva, del món. Com sabem, el naturalista francès s'oposava fervorosament a les tesis de Linné, el pare de la sistemàtica i de la nomenclatura binominal de les espècies que fins avui s'aplica en biologia. En un altre discurs, titulat Sobre la manera d'estudiar i de tractar la història natural (De la manière d'étudier et de traiter l'histoire naturelle, 1749), Buffon critica severament diferents sistemes de classificació d'organismes vius (en particular el de Linné), que considera falsos perquè en lloc de contemplar els organismes en la seva complexitat, estableixen unes classificacions $i$ catalogacions arbitràries $i$, en definitiva, simplistes; en conseqüència, no vacil·la a equiparar-los a simples diccionaris o glossaris de termes, tot qüestionant-ne el valor científic. En la natura, assevera Buffon, només existeixen individus; en canvi, els gèneres, els ordres i les classes són producte de la nostra imaginació. En la seva novel·la, Domínguez li fa apuntar aquestes paraules:

Des del primer volum de la Historia natural he atacat amb força els amants de les classificacions, i entre ells, he criticat durament el Systema naturae de Linné. Les meves crítiques han estat exclusivament acadèmiques: les espècies són alguna cosa més que noms arbitraris, i per a poder comprendre totes les característiques d'una espècie no n'hi ha prou amb la descripció de l'individu, sinó que hem d'estudiar tota la història d'aquest animal particular: la seua procreació, el seu període de gestació, el moment de naixement, el nombre de cries, l'atenció dispensada pel pare i mare, l'educació, els seus instints, l'hàbitat i la dieta, la forma d'aconseguir l'aliment, els seus costums, ardits i mètodes de caça. (Domínguez, 2005, pp. 192-193)

Estudiar "el moment de naixement, el nombre de cries, l'atenció dispensada pel pare i mare, l'educació, els seus instints, l'hàbitat i la dieta, la forma d'aconseguir l'aliment, els seus costums, ardits i mètodes de caça" i d'altres

Història Natural. Hi reuneix moltes informacions d'estudis i recerques, però també d'amors i duels. Les guerres entre erudits esdevenen un camp d'observació extraordinari de la naturalesa humana. [...] El capítol dedicat a l'ingrés a l'Acadèmia de Ciències, amb la citació de llargs paràgrafs del Discurs sobre l'estil, té un pes fonamental en la novel·la, que en segueix les directrius" (2004, pp. 22-23). No obstant això, paga la pena observar que en la novel·la de Domínguez s'evoca també, a mode de camí descartat, un altre model (auto)discursiu de l'època, que no podia mancar en una novel·la que es volia panoràmica. Es tracta de la manera de narrar i construir el relat de la pròpia vida, manera ideada i posada en pràctica per Rousseau en les seves Confessions. El narrador de la novel·la la rebutja obertament, en considerar l'obra de Jean-Jacques "una autèntica exhibició de les seues petites misèries humanes..." (Domínguez, 2005, p. 187), encara que en un altre moment, colonitzat per la veu autorial -procediment que l'escriptor, amb clara intenció didàctica, empra força sovint en aquest novel·la, en detriment inevitable de la versemblança del relatacaba per considerar que Rousseau "ha creat una nova forma d'escriure, d'expressar els sentiments, i quasi amb seguretat la literatura dels anys vinents vessarà d'aquest sentimentalisme líric i expressiu" (p. 223). 
elements que podríem afegir-hi, vet aquí l'objectiu que es planteja Domínguez en Les confidències. I si a l'hora de fixar aquest objectiu sembla haver-se inspirat en l'obra del francès, també ho fa en la tria del mètode. "L'única manera de fer avançar la ciència és treballar en la descripció i la història dels elements que la conformen com a objecte d'estudi" ${ }^{18}$, afirma. D'una banda, la història entesa en un sentit que potencia el factor temporal -presentació d'un procés vital i intel·lectual- i, de l'altra, la descripció del medi en què es desenvolupa aquest procés com si fos una pintura panoràmica són, justament, dues perspectives que l'autor valencià ha procurat fer coincidir en la seva novel·la, a fi d'aportar una veritat sobre "l'animal particular" anomenat Buffon. Domínguez hi estructura la història del personatge seguint el mètode manllevat del mateix George-Louis Leclerc, i és aquest el tret principal de "l'estil" (entès en el sentit ampli, buffonià) que caracteritza Les confessions.

\section{EL SECRET DE GOETHE}

Trobem una inspiració anàloga en $E l$ secret, la segona novel·la del tríptic del segle XVIII, amb la diferència que en aquest cas la referència a l'obra de l'autor retratat és molt més evident, ja que es materialitza en diferents nivells del relat. Tant és així que l'escriptor valencià construeix la seva novel·la en diàleg directe amb Viatge a Itàlia (Italienische Reise ${ }^{19}$ ) de Johann Wolfgang Goethe. En El secret la veu narrativa pertany al transsumpte literari de Johann Heinrich Wilhelm Tischbein, un pintor alemany que va coincidir amb Goethe a Roma i va viatjar amb ell a Nàpols. Paisatgista, retratista, autor de gravats i dibuixos, va passar a la posteritat com Goethe-Tischbein ${ }^{20}$ (o "el Tischbein de Goethe", fórmula que el narrador de la novel·la de Domínguez empra en la seva autopresentació) pel seu oli Goethe en la campanya romana (Goethe in der römischen

18 “[M] ais le seul et le vrai moyen d'avancer la science est de travailler à la description et à l'histoire des différentes choses qui en font l'objet" (Buffon, 1835, p. 52).

${ }^{19}$ Goethe, ja conegut i celebrat com a autor del Werther, va viatjar per la Península Itàlica en els anys 1786-1788; el relat d'aquest recorregut, però, es va publicar força més tard: una primera part, que abraçava el trajecte de Carlsbad a Roma i la seva primera estada a la ciutat eterna, va veure la llum l'any 1816; una segona part, corresponent a la visita a Nàpols i Sicília, va arribar a mans dels lectors l'any 1817. El relat de la segona estada a Roma es va publicar l'any 1829 (juntament amb la reedició de les parts anteriors), i en aquest cas Goethe es va servir dels seus diaris de viatge, de les cartes que durant la seva italienische Reise anava enviant a diferents persones residents a Weimar, així com de diferents esbossos i articles presentats en d'altres ocasions (vg. Hertz, 1980, p. 548).

${ }^{20} \mathrm{En}$ El secret, el mateix personatge de Goethe prediu aquest fet en una d'aquelles prolepsis retòriques que anul·len l'efecte de versemblança, observades anteriorment en Les confessions (Domínguez, 2005, p. 162). 
Campagna), que va realitzar l'any 1787 i que es convertiria en la seva obra més coneguda. Goethe evoca la figura del pintor en diverses ocasions en el seu Viatge a Itàlia, de manera que el relat homodiegètic del Tischbein literari es basteix en $E l$ secret com una mena de contradiscurs, que aporta un punt de vista diferent sobre la història de les relacions entre ambdós artistes i algunes situacions i experiències que van viure plegats. En l'apartat que obre la novel·la, aquesta relació es presenta com a pivot del discurs del narrador. El fet de ser "el Tischbein de Goethe" constitueix una tara, un defecte que impulsa l'acte narratiu, que li dóna raó de ser i sentit, i atorga al narrador una força imprescindible per "explicar el seu cas", el d'un home condemnat a viure amb la petja indeleble d'un altre. A la vegada, aquest mateix acte narratiu resulta l'oportunitat de presentar una imatge de Goethe alternativa respecte a l'autoretrat que ell mateix havia deixat en Viatge a Itàlia; o, el que és el mateix, en la novel·la de Domínguez la figura literària del "Tischbein de Goethe" es proposa pintar, en un joc de reflexos, un (altre) retrat del "Goethe de Tischbein" i, a partir d'aquí, aportar una versió pròpia dels esdeveniments evocats anteriorment pel poeta alemany en el seu relat del viatge.

En El secret tornem a trobar la mateixa recerca de l'efecte d'autenticitat que hem observat en Les confessions. D'acord amb una suposada "nota de l'editor al lector", afegitó final de la novel·la, el llibre transcriu un inèdit de Tischbein, donat a conèixer en ocasió del 250 aniversari del naixement de Goethe (que es va escaure l'any 1999; la novel·la de Domínguez va ser publicada l'any següent). I com que, efectivament, Tischbein és l'autor d'unes memòries en què tractava, entre d'altres, del viatge a Nàpols realitzat en companyia de Goethe ${ }^{21}$, aquest pretès "testimoni inèdit" és presentat com un text complementari, escrit amb "la voluntat d'aprofundir i detallar [...] el perfil del més gran escriptor que fins ara ha produit Alemanya" (Domínguez, 2000, p. 15).

Un cop dit això, paga la pena observar l'evolució que es produeix en la pràctica de fer intervenir la figura autorial, emprada per Domínguez en el seu tríptic del segle XVIII. En Les confidències, el text principal està precedit per un preàmbul en què la procedència del suposat manuscrit s'explica per la visita de Monsieur Domínguez a la Cave del Muséum Nationale (sic) d'Histoire Naturelle de París; l'epíleg torna a donar la paraula a l'àlter ego de l'autor, de manera que el relat homodiegètic del narrador (la figura literària de Buffon) queda emmarcat pel -i subordinat al- discurs de la figura autorial i la història de la seva aventura

${ }^{21}$ En la seva autobiografia Aus meinem Leben (Braunschweig, 1861). El Tischbein literari, narrador del llibre de Domínguez, s'hi refereix tot dient: “[J]a fa un grapat d'anys vaig escriure les meues memòries i les referències a Goethe foren molt escasses; tan pobres i insignificants que alguns lectors amics, als quals vaig deixar llegir el manuscrit, es quedaren defraudats" (Domínguez, 2000, p. 14). 
parisenca. En El secret el relat principal és seguit de la suposada nota de l'editor que acabem de comentar ${ }^{22}$. En El retorn de Voltaire, per la seva part, el relat principal ve acompanyat per una nota, afegida al final del llibre, en què l'autor facilita unes dades històriques referents a les circumstàncies de la mort i l'enterrament de l'autor de Càndid. Més endavant, en un apèndix bibliogràfic, s'evoquen les obres crítiques crucials per al coneixement de la seva vida, creació i l'època en què va viure. Sense posar-nos a esbrinar ara les raons que haurien portat l'autor a aplicar aquest procediment amb tanta recurrència, és important subratllar el procés d'independització del relat principal que s'opera en el conjunt de les novel·les comentades i que potser s'ha d'interpretar com a prova de la maduresa literària de l'autor, cada cop més destre i segur de sí mateix en la invenció de la trama i la construcció del conflicte novel·lesc ${ }^{23}$. Comparades amb la falsa autobiografia de Buffon, les memòries de Tischbein constitueixen un discurs força més autònom, que tan sols al final del llibre és presentat com un testimoni publicat per un editor -una màscara que es posa l'autor-, el qual no exerceix cap paper efectiu en la configuració de l'univers ficcional. Finalment, en El retorn de Voltaire, la darrera entrega del tríptic, el relat principal assoleix una completa independència.

Tot reprenent el nostre comentari sobre les estratègies narratives de $\mathrm{El}$ secret, constatem que el diàleg amb Viatge a Itàlia es suggereix ja a nivell de l'estructura del text, que es troba dividit en apartats titulats com els noms de les ciutats en què es desenvolupa l'acció: "Roma", "Nàpols" i "Weimar". Aquesta organització, en línies generals, segueix la lògica de la distribució de continguts en el llibre de Goethe ${ }^{24}$. Retrobem un mateix joc de miralls en la representació de la relació entre els dos personatges, que l'autor de Viatge a Itàlia havia reflectit amb relativa continuïtat en les planes del seu llibre: des del moment en què es van conèixer (que va coincidir amb l'arribada de Goethe a la ciutat eterna) fins a un significatiu refredament de les relacions (assenyalat en un parell d'anotacions de l'autor del Werther, si no del tot explícites, sí força expressives) ${ }^{25}$,

\footnotetext{
${ }^{22}$ I encara que, com escriu Genette, un procediment d'aquesta mena "[...] repousse du même coup l'auteur réel dans le rôle fíctivement modeste de simple "éditeur", ou présentateur - du moins lorsque son nom, différent de celui du héros, continue de figurer lui aussi au paratexte [...]" (Genette, 1987, p. 305), no queda dubte que la figura autorial plana tant sobre el relat constituït per les suposades memòries del comte de Buffon (en Les memòries), com sobre el de Tischbein (en El secret).

${ }^{23}$ També Guillamon (2007, p. 23) afirmava que El secret és una novel·la "més madura" que Les confidències.

${ }^{24}$ Viatge a Itàlia inclou seccions dedicades a dues estades a Roma ("Roma" i "Segona estada a Roma"), i dos apartats amb el títol de "Nàpols", corresponents a dues visites de Goethe a aquesta ciutat, realitzades abans i després del viatge a Sicília.

${ }^{25}$ En l'apartat corresponent a la segona estada a Roma, Goethe (2000) apunta: "No podeu imaginar com me n'ha estat de profitós però també d'incòmode aquest any absolutament viscut
} 
passant pel viatge a Nàpols efectuat conjuntament pels dos artistes i la separació que va seguir. Les falses memòries de Tischbein semblen estar construïdes a partir d'aquestes observacions, de manera que la relació esbossada amb poques pinzellades en el llibre de Goethe, es desenvolupa i complementa amb anècdotes i explicacions exposades des de la perspectiva del pintor.

Si el propòsit de Les confessions és, en gran mesura, divulgatiu ${ }^{26}$-com hem vist, es tracta de presentar la vida i l'obra de Buffon i també el seu mètode, tot posant-lo en pràctica (narrativa)-, el motiu que hauria impulsat Domínguez a escriure $E l$ secret ja no resulta tan explícit. Certament, hi ha la possibilitat de veure-hi un intent de "rehabilitar" Tischbein, "maltractat" en Viatge a Itàlia, i de "rescatar de l'oblit" la seva figura, eclipsada, per l'ombra del savi de Weimar"27; d'altra banda, però, cal observar que aquesta novel·la de Domínguez ens proposa un relat "bessó" respecte al llibre de Goethe, reprenent, en definitiva, les idees allí contingudes. Això no vol dir, certament, que es tracti d'una mera imitació. A través dels comentaris de Tischbein, Domínguez aconsegueix presentar, desenvolupar o també aclarir certs aspectes de les diferents cares de la creació i el pensament de Goethe, que es poden resumir en la tríada literatura - ciència - pintura. D’aquestes, probablement la menys coneguda (i, per tant, la que mereix més la pena ser divulgada) és l'especulació científica, que el mateix poeta considerava com a part importantíssima (si no la més important) de la seva activitat intel·lectual: "si el meu nom passa a la posteritat serà fonamentalment per les meues idees científiques”, diu en El secret (2000, p. 225).

En la novel·la s'evoquen llavors els principals camps d'activitat científica de Goethe: la geologia, la mineralogia, la botànica, la zoologia, l'anatomia, l'òptica... Tot resseguint el trajecte descrit en Viatge a Itàlia, Domínguez el fa

entre estranys, sobretot perquè Tischbein -sigui dit entre nosaltres- no féu el que jo esperava. És realment un bon home, però no pas tan net, obert i natural com en les seves cartes. Només de paraula puc descriure el seu caràcter, perquè no voldria pas fer-li mal, què pot valdre, però, una descripció així? La vida d'una persona és el seu caràcter. Ara espero poder disposar de Kayser, $i$ això em fóra una gran joia" (p. 447). I en un altre moment, sempre en referència a Tischbein, assenyala: "La convivència amb ell era quelcom prou agradable, bé que a la llarga un cert mal hàbit podia pertorbar-la, efectivament: tot el que es proposava de fer quedava embolcallat per una mena d'incertesa que malgrat l'absència de tota mala voluntat podia perjudicar els altres i disgustar-los" (p. 573).

${ }^{26}$ També semblen tenir una finalitat didàctica -ja que evoquen certa tradició literària- unes breus sinopsis aparegudes sota els títols dels capítols, que tot i no arribar a l'extensió de l'argumentum entès en el sentit estricte (és a dir, tal com es presentava en els textos dels primers segles de l'Edat Moderna), orienten el lector en les matèries tractades en cada apartat.

${ }^{27}$ Se m'acut aquesta explicació quan llegeixo les raons - de natura semblant, de fet- que van impulsar Domínguez a escriure El retorn de Voltaire, segons ell mateix confessava en una entrevista: "Buffon i Voltaire es duien prou malament i jo vaig tenir la sensació d'haver maltractat Voltaire al primer llibre i em va venir la idea de dedicar-li una novel·la” (Bombí, 2007, p. 11). 
pujar els pendents del Vesuvi en erupció, armat d'un martell de geòleg, i aprofita per esmentar les possibles raons de la presència de petxines en la lava volcànica, que tant havia preocupat els naturalistes del Segle de les Llums. S'hi comenten igualment els coneixements zoològics i anatòmics de Goethe (en particular, els seus estudis d'osteologia i el descobriment de l'os intermaxil·lar); òbviament, l'autor de la novel-la no s'oblida de recordar-nos que va ser justament el poeta de Weimar qui va proposar el terme "morfologia", amb el qual va deixar un segell personal en la ciència moderna. En definitiva, d'acord amb la visió de Domínguez, el poeta-científic és un visionari a la recerca de les lleis universals de la natura.

Comentari a part ha merescut la investigació botànica de Goethe. Al costat d'unes lliçons de botànica més o menys erudites (carregades de retòrica, en algun cas) que el personatge imparteix als seus companys i que tracten sobre diferents espècies vegetals (l'arbre de judes, el ginkgo, etc.), i d'alguna "comparació vegetal" en boca del protagonista ("necesite l'anonimat com la planta necessita la llum per a créixer i fer els seus fruits" [Domínguez, 2000, p. 34]), s'hi evoquen les lectures dels tractats taxonòmics de Linné $i$ "experiments sobre el creixement de les plantes" realitzats per Goethe, però sobretot el tema de la planta arquetípica, que el poeta de Weimar, nascut entre les boires septentrionals, esperava trobar en el lluminós Mediterrani. La teoria de la Urpflanze, la planta de què procedeixen totes les plantes, pren cos justament durant el seu Grand Tour; Domínguez (2005, p. 143) la resumeix tot fent referència directa als continguts presentats en Viatge a Itàlia ${ }^{28} \mathrm{i}$ al concepte de "polaritat" -un estat d'atracció i repulsió (vg. Miller, 2009, p. XIX)- que Goethe considera com una de les forces motrius de la natura.

28 “Com podria reconèixer jo que tal formació o tal altra són o no una planta si no estiguessin conformades totes d'acord amb un model únic?" (Goethe, 2000, p. 412), es pregunta el poeta. I és "sota el cel" del Mediterrani, a Palerm i Nàpols, on li sembla haver trobat respostes a les seves inquietuds, segons anuncia amb un to triomfant en una carta dirigida a J. G. Herder: "També he de confiar-te que he arribat molt a prop del secret de la gènesi i l'organització de les plantes, molt més simple del que hom pugui pensar. Sota aquest cel és possible de realitzar les observacions més interessants. [...] La planta arquetípica serà la creació més meravellosa del món, i segurament que la mateixa naturalesa me l'envejarà. [...] He comprès, en efecte, que en aquell òrgan de la planta anomenat sòlitament per nosaltres fulla s'amaga un autèntic Proteu, capaç d'assumir i manifestar qualsevulla forma. Abans o després, la planta és sempre només fulla, tan indissolublement unida al germen futur que hom no pot imaginar l'un sense l'altra. Concebre aquesta idea, mantenir-la i verificar-la en la natura és una empresa que ens immergeix en un estat agredolç" (Goethe, 2000, pp. 412-413). Per a Goethe, la "metamorfosi de les plantes", a què més tard dedicarà un treball publicat sota aquest mateix títol (1790) -evocat en El secret (Domínguez, 2000, p. 224)-, és el procés que permet a la "fulla" inicial (i proteica) transformar-se per generar diferents òrgans vegetals. 
Ara bé, tenint en compte el caràcter de "relats bessons" de Viatge a Itàlia de Goethe i la novel·la que estem analitzant -un tret que s'expressa en la similitud d'estructures narratives emprades, temes tractats i situacions recreades-, algú podria preguntar-se si la novel·la de Domínguez és un instrument de divulgació indispensable. L'assumpció que aquest fet s'acompleix significa suposar que el lector, de qui depèn en última instància l'elecció de les fonts d'informació, preferirà conèixer el pensament del poeta alemany a través de la novel·la de l'escriptor valencià que llegint directament el diari de Goethe, el qual -si volem tornar un cop més al Discurs sobre l'estil de Buffon- "va passar a la posteritat" pel fet d'estar "ben escrit", pel seu estil elevat i noble. Sigui com sigui, del que no hi ha dubte és que a diferents sectors del públic d'avui el llibre d'un autor actual, que, a més, es fixa l'objectiu de "vulgaritzar"29 , sí resulta més assequible $-\mathrm{i}$, així mateix, preferible- que l'obra d'un clàssic.

\section{LA DIVULGACIÓ COM A PRÀCTICA DE MEDIACIÓ}

A la vegada, no cal perdre de vista un altre aspecte important del tema que ens ocupa, és a dir, les característiques de la tasca de divulgació dels coneixements científics que Domínguez es proposa portar a terme en els seus llibres, qüestió que ell mateix abordava en el fragment que he citat al principi d'aquest article. Chassot (2011, pp. 370-371) ens recorda que la pràctica de difusió del saber ha estat objecte de reflexió i de polèmiques al segle XVIII. Els il·lustrats, fins $i$ tot els que estaven més compromesos amb la tasca divulgadora, no deixaven d'interrogar-se sobre els límits i, en definitiva, la legitimitat d'aquesta activitat. Alguns problemes que s'hi plantegen són, per exemple, com reconciliar el rigor amb el plaer, la serietat de l'estudi amb l'atractiu de la forma de presentar els materials, o la solidesa amb l'elegància. En resposta a aquests dubtes $\mathrm{i}$ inquietuds, Jeanneret (vg. Chassot, 2001, p. 371) proposa reconsiderar la natura de l'activitat divulgativa, tot destacant que els continguts que transmet són d'un caràcter essencialment diferent del dels coneixements científics. La divulgació -argumenta- inscriu els descobriments científics en la nostra visió del món, transforma el treball científic en una pràctica social, la ciència en cultura $i$, com a tal, és, en primer lloc, una mediació ${ }^{30}$.

\footnotetext{
${ }^{29}$ Faig servir el terme sense cap càrrega pejorativa.

30 "Plutôt que de mesurer et déplorer des écarts entre le texte du vulgarisateur et sa source scientifique, mieux vaut analyser cette opération de médiation entre science et société", adverteix Chassot (2001, p. 371). En un sentit semblant, Paul Caro (1996) afirma: "Il y a une chose que la communauté scientifique a beaucoup de mal à admettre. Contrairement à ce qu'elle pense, la vulgarisation scientifique n'est pas la traduction du langage scientifique en un langage plus simple. La vulgarisation ne s'apparente pas à la didactique ou à l'éducation. C'est tout autre chose.
} 
Aquesta és, al meu parer, la perspectiva que és interessant aplicar en la lectura de les dues novel-les de Martí Domínguez que he comentat en aquest article. La seva narrativa, amb les tècniques i les estratègies que proposa-que, seguint Buffon, hem anomenat el seu "estil"- es pot tractar -tot i que no únicament, és clar- com una pràctica de transmissió de coneixements entre ciència i societat. Certament, per poder evocar els aspectes més representatius de l'activitat científica dels dos naturalistes i esbossar el seu context històric, Domínguez havia de fer una tria de continguts $i$, a més a més, intentar presentar-la d'una forma "atractiva", cosa que en algun cas pot arribar a ser sinònim de "simplificada". També és veritat que en les novel·les de l'escriptor valencià s'observen certa opulència retòrica o algunes imperfeccions en la construcció dels personatges, de manera que, en comparació (inevitable, donada la seva natura dialògica) amb les creacions de les figures senyeres del segle XVIII europeu, els seus llibres no deixen de ser "obres menors". Això no obstant, també és cert que, com escrivia Guillamon en un comentari referent a Les confessions, però perfectament transferible a $E l$ secret, en les novel·les que estem comentant "la recreació està tan ben aconseguida que convida a tornar a l'original" (2004, p. 22). En aquest sentit -i reprenent la pregunta exposada fa un moment- no té importància si el lector arriba a conèixer episodis de la història de les ciències naturals a través dels textos de Domínguez, o si en veure el nom de Buffon o Goethe en la portada del llibre ${ }^{31}$ decideix més aviat "tornar als clàssics" (del pensament científic, en aquest cas), o si ho fa després de la lectura d'alguna de les novel·les. Podríem dir que en aquest cas la via d'arribar al coneixement no és tant important com el mateix fet d'arribar-hi. D'una o altra forma les novel·les de Domínguez animen a emprendre aquest camí, i en això consisteix el seu valor i i el seu èxit com a instruments de mediació entre ciència i societat. Missió acomplerta.

C'est un genre littéraire à part entière, qui est apparu sous ses différentes formes, à la fois écrites et imagées, dès la naissance de la science moderne, au milieu du XVIIe siècle" (p. 90).

${ }^{31}$ Vista des d'aquesta perspectiva, la tria de títols de les novel·les de Domínguez, que ostenten els noms dels personatges presentats en els llibres, es pot considerar com una estratègia de divulgació més. 


\section{BIBLIOGRAFIA}

Bombí, F. (2007). Llegir els il·lustrats és un refugi en moments de dubte. Avui Cultura (Barcelona), 12 d'abril, 10-11. Obtingut de http://www.traces.uab.es/tracesbd/avui/av07209.pdf

Buffon, G.-L. Leclerc, Comte de (1835). Euvres complètes, vol. 1. Paris: Pourrat Frères, Éditeurs.

- (1843). Discours sur le style et autres discours académiques. Paris: Librairie de L. Hachette.

Caro, P. (1996). La science à la tv est un genre littéraire. Recherche, 288 (juny), 90 [entrevista]. Obtingut de http://www.larecherche.fr/savoirs/autre/paul-caro-science-a-tv-est-genre-litteraire01-06-1996-73390

Castells, A. (2007). El Voltaire aïllat em recorda l'autor en català a València. Avui Cultura (Barcelona), 8 de gener [entrevista].

Chassot, F. (2011). Le dialogue scientifique au XVIII ${ }^{e}$ siècle. Posterité de Fontenelle et vulgarisation des sciences. Paris: Classiques Garnier.

Domínguez, M. (2000a). Bestiari. València: Edicions $3 i 4$.

- (2000b). El secret de Goethe. Barcelona: Cercle de Lectors.

- (2005). vg. Domínguez Romero, M.

- (2010). La creació. Barcelona: Oficina Ponti.

- (2014). El somni de Lucreci. Una història de la llibertat del pensament. Barcelona: Proa.

Domínguez Romero, M. (2005). Les confidències del comte de Buffon (Una època de la natura). València: Eliseu Climent.

Genette, G. (1987). Seuils. Paris: Éditions du Seuil.

Goethe, J. W. (2000). Viatge a Itàlia (trad. i notes de R. M. Bofill). Barcelona: Columna.

Guillamon, J. (2007). Martí Domínguez torna a València vestit de lapó. Caràcters (València), 27, 22-23.

Hertz, P. (1980), Od wydawcy. Dins J. W. von Goethe, Podróż włoska (trad. [al polonès] de H. Krzeczkowski). Warszawa: Państwowy Instytut Wydawniczy.

Hoquet, T. (2005). Présentation des Époques de la Nature de Buffon. Obtingut de http://www.aca demie-polonaise.org/pl/images/stories/pliki/PDF/Roczniki/R8/hoquet.pdf

- (2010). History without Time. Buffon's Natural History as a Nontmathematical Physique. Isis, 101, 30-61.

Malesherbes, Chrétien Guillaume de Lamoignon de (1798). Observations sur l'Histoire Naturelle Générale et Particulière de Buffon et Daubenton, vol. I (transcripció de S. Schmitt). Paris: Charles Pougens. Obtingut de http://www.buffon.cnrs.fr/i-corpuspic/tab/extraits/lamoignonmalesherbes/ObservationsLamoignon-Malesherbes.pdf

Miller, G. L. (2009). Introduction. Dins J. W. von Goethe, The Metamporphosis of plants (pp. XVXXXI), Cambridge: The MIT Press.

Roger, J. (1989). Buffon. Un philosophe au Jardin du Roi. Paris: Fayard.

Rousseau, J.-J. (1826). Euvres, vol. XVIII. Correspondance, vol. II. Paris, Werdet et Lequien Fils.

Sòria, E. (2004). Entre natura i art. Caràcters (València), 27, 26-27. 